\title{
Contribution of non-work and work-related risk factors to the association between income and mental disorders in a working population: the Health 2000 Study
}

\author{
M Virtanen, ${ }^{1,4}$ S Koskinen, ${ }^{2}$ M Kivimäki, ${ }^{1,5}$ T Honkonen, ${ }^{1} \mathrm{~J}$ Vahtera, ${ }^{1} \mathrm{~K}$ Ahola, ${ }^{1}$ \\ $\mathrm{J}$ Lönnqvist $^{3}$
}

${ }^{1}$ Finnish Institute of

Occupational Health, Helsinki,

Finland; ${ }^{2}$ National Public Health Institute, Department of Health and Functional Capacity, Helsinki, Finland; ${ }^{3}$ National Public Health Institute, Department of Mental Health and Alcohol Research, Helsinki, Finland, and University of Helsinki, Department of Psychiatry, Helsinki University Central Hospital (HUCH), Helsinki, Finland; ${ }^{4}$ University of Helsinki, Department of Psychology, Helsinki, Finland;

${ }^{5}$ University College London Medical School, International Centre for Health and Society, Department of Epidemiology and Public Health, London, UK

Correspondence to: M Virtanen, Finnish Institute of Occupational Health, Topeliuksenkatu 41 aA FI-00250 Helsinki, Finland; marianna.virtanen@ttl.fi

Accepted 3 August 2007

\begin{abstract}
Objectives: To examine the contribution of non-work and work factors to the association between income and DSM-IV depressive and anxiety disorders in a working population.
\end{abstract}

Methods: A representative sample of the Finnish working population aged 30-64 (1667 men, 1707 women) in 2000-2001 responded to a survey questionnaire on nonwork factors (marital status, housing conditions, non-work social support, violence victimisation, smoking, physical symptoms), work factors (job demands, job control, social support at work, educational prospects, job insecurity) and household income. Somatic health was examined in a standard health examination. The 12-month prevalence of depressive and anxiety disorders was examined with the Composite International Diagnostic Interview.

Results: The risk of having a depressive or anxiety disorder was 2.8 times higher in the low-income group than in the high-income group among men and 2.0 times higher among women. For men, non-work and work factors explained $20 \%$ and $31 \%$ of this association, respectively. For women, the corresponding figures were $65 \%$ and $23 \%$.

Conclusions: Low income is associated with frequent mental disorders among a working population. In particular, work factors among men and non-work factors among women contribute to the income differences in mental health.

Mental disorders, such as depressive and anxiety disorders, are relatively common and predict work disability as much or even more than many other chronic conditions such as cardiovascular diseases. ${ }^{12}$ The 12-month prevalence of depressive and anxiety disorders in general populations varies between $4 \%$ and $11 \%$, and $4 \%$ and $19 \%$, respectively. $^{3-5}$ Socioeconomic inequalities in mental health are well documented and indicate a higher prevalence and incidence of mental health problems in socially disadvantaged populations. ${ }^{5-21}$ However, only a few studies have used the Composite International Diagnostic Interview (CIDI) or other standardised diagnostic interview methods to study the association between socioeconomic position and the most common mental disorders. ${ }^{5-12} 1521$ The Finnish Health 2000 Study showed no association between educational level and mental disorders. ${ }^{4}$ As an indicator of socioeconomic position, several studies have used material standard of living which has included, for example, family income, housing, car ownership, etc. ${ }^{19}$ In one study, socioeconomic position was measured by means of income per consumption unit which predicted incidence of psychiatric disorder. ${ }^{7}$ While earlier studies have included unemployed and economically inactive subjects, it is not known whether socioeconomic inequalities in mental health can also be found among the working population.

Socioeconomic inequalities in mental health have been explained by two theoretical frameworks. The social causation hypothesis states that barriers (eg, low income) to achieving highly valued goals (eg, goods, services, honour, job control) produce socioeconomic inequalities in health. ${ }^{22}{ }^{23}$ However, according to the social selection hypothesis, the rate of psychopathology among people in low socioeconomic positions is a function of an inter- and intragenerational sifting process in which unhealthy individuals tend to drift down from a high socioeconomic position or fail to rise from a low position. ${ }^{23}$ Empirical evidence exists for both the social causation and social selection assumptions. ${ }^{6} 8$

Adverse life events, financial hardship and psychosocial life stress are among the factors that have been shown to have a role in explaining the social gradient in mental health. ${ }^{13} 14161820$ Other potential risk factors for mental disorders, which also may be related to socioeconomic gradient, are marital status (not living with a partner), ${ }^{24} 25$ smoking, ${ }^{24}$ somatic diseases,${ }^{24}$ poor housing conditions, ${ }^{25}{ }^{26}$ violent victimisation ${ }^{26}{ }^{27}$ and lack of social support. ${ }^{26}{ }^{27}$

Of the work-related factors, psychosocial work stress has been shown to predict mental health problems. ${ }^{28-35}$ Two leading theoretical models explain the effect of work stress on health: the job strain model ${ }^{33} 34$ and the effort-reward imbalance model. ${ }^{32}$ The key issues of the job strain model are high job demands, low job control and low social support, ${ }^{33}{ }^{34}$ whereas the principal components of the effort-reward imbalance model are high demands and low rewards, such as high job insecurity $^{35}$ and lack of educational prospects at work. ${ }^{32}$ Most of these work stress factors have been found to be more common among employees with a low socioeconomic position and have explained a substantial part of the socioeconomic gradient for psychological distress. ${ }^{13} 14161820$ In a recent review focusing on the gender differences in mental 
health, men and women were suggested to be different in relation to sensitivity to various life stressors. ${ }^{36}$ Women seem to be more affected by crises involving children, housing and reproduction (eg, postpartum depression) rather than those involving work. In fact, work characteristics have been shown to be more strongly related to socioeconomic differences in psychological distress among men than among women. ${ }^{14} 1620$ However, as earlier reports have concerned self-reported psychological distress or symptoms, it is unclear if these results apply to clinically significant depressive and anxiety disorders, as defined by DSM-IV diagnostic criteria in a population-based sample.

This study examined the contribution of non-work and work factors to the association between income and DSM-IV depressive and anxiety disorders in a working population.

Based on earlier literature, we stratified our analyses by gender.

\section{METHODS}

\section{Sample and procedure}

A multidisciplinary epidemiological health survey, the Health 2000 Study, was carried out in Finland in 2000-2001. The twostage stratified cluster sample was representative of the Finnish population and included 8028 persons aged 30 years or over. ${ }^{37}$ The stratification and sampling were conducted as follows. The strata were five university hospital districts, each serving about 1 million inhabitants and differing in several features relating to geography, economic structure, health services and the socio-demographic characteristics of the population. First, the 15 largest cities were included with a probability of 1 . Next, within the five districts, 65 other areas were sampled according to the probability proportional to population size (PPS) method. Finally, from each of these 80 areas, a random sample was drawn from the National Population Register. A total of $75 \%$ of the original sample participated in the CIDI interview. Compared to participants in the CIDI interview, those who only attended the home interview were found to score significantly more symptoms on the Beck Depression Inventory (BDI), were older, were more often single or widowed, and had a low level of education. ${ }^{4}$ The detailed methodology of the project has been published previously. $^{4}{ }^{37}$

The data collection phase started in August 2000 and was completed in June 2001. A total of 7419 persons (93\% of the 7977 persons alive on the first day of the first phase of the survey) attended at least one phase of the study. They were interviewed at home, where they were also given a questionnaire to be returned at the clinical health examination. During the interview, the respondents received an information leaflet and their written informed consent was obtained. The Health 2000 Study was approved in 2000 by the Ethics Committee for Epidemiology and Public Health in the Hospital District of Helsinki and Uusimaa in Finland.

Of the total sample, 5871 persons were of working age (3064 years old). Of this base population, 5152 persons were interviewed (88\%), 4935 persons returned the questionnaire $(84 \%)$ and $4886(83 \%)$ participated in the health examination, including the structured mental health interview (CIDI). The final sample of our study comprised the 3374 participants (1667 men, 1707 women) who were employed at the time of the interview.

\section{Income level}

We determined the income level of the participants using the definition of low income as suggested by the Organisation for Economic Co-operation and Development (OECD). In that definition, people have a low income if they belong to a household in which the income per consumption unit is either lower than $50 \%$ or lower than $60 \%$ of the national median income. In Finland, there is no official definition for low-income level. In this study, we used $50 \%$ of the median income as a cutoff point for low income. The cut point for the low-income consumption unit (€7340/year for 2001) was obtained from Statistics Finland (the government's official statistical office, personal information, June 2007). Because no official cut-off points have been defined for high income, the high-income group was derived from the highest tertile of the working population in our dataset, and the intermediate income group comprised those who fell between the low- and high-income groups. Information on household income and the number of adults and children in the household was derived from the home interview. Gross income was transformed to net income using a tax calculation programme (year 2001) developed for this purpose. As suggested in the OECD directive, the number of consumption units was calculated as follows: the first adult in the household was weighted by 1 and each following adult was weighted by 0.7 . Each child in the household was weighted by 0.5. The income per consumption unit was calculated by dividing the household income by the number of consumption units.

\section{DSM-IV depressive and anxiety disorders}

Mental health status was based on a computerised version of the WHO Composite International Diagnostic Interview (MCIDI) as a part of the comprehensive health examination. The standardised CIDI interview has been shown to be a valid instrument to assess common non-psychotic mental disorders. ${ }^{38}$ The program uses operationalised criteria for DSM-IV diagnoses and allows the estimation of DSM-IV diagnoses for major mental disorders. ${ }^{39}$ The 21 interviewers were primarily nonpsychiatric health care professionals trained to administer the CIDI interview by psychiatrists and physicians who had been trained by a WHO authorised trainer. Mental disorders were assessed using DSM-IV definitions and criteria. The participant was identified as a case if he/she fulfilled the criteria for a depressive or anxiety disorder, which are the most frequent mental disorders in the general populations. Depressive disorder meant a diagnosis during the previous 12 months of a major depressive disorder or dysthymia, while anxiety disorders included diagnoses of panic disorder (with or without agoraphobia), generalised anxiety disorder, social phobia, phobia not otherwise specified and agoraphobia (without panic disorder).

\section{Demographic factors}

Information on gender and age was collected in the home interview.

\section{Non-work factors}

\section{Home interview}

Information on marital status was collected in the home interview and subjects were divided into two groups: those who were married or cohabiting and those who were divorced, widowed or single.

Housing disadvantages were examined in the home interview with 12 questions with yes/no alternatives considering pro- 
blems with residential crowding, laundering possibilities, doors, groundsills, worktops, dampness, chilliness, draft, fug, noise, dirt or dust from traffic or industry, and poor means of transport. A mean score was calculated (range from 0 to 12 points) in which a higher level indicates more disadvantage in housing conditions.

Smoking status was obtained from home interview and subjects were classified as non-smokers versus current smokers.

\section{Survey}

Four survey questions based on the scale by Sarason et a lt0 $^{40}$ assessed social support outside work. In that measure, the participants marked who (spouse, close relative, friend, close neighbour, someone else close) would help or support them (1) when they were exhausted, (2) when they were depressed, (3) when they needed practical help, or (4) in any event. A sum score was calculated ranging from 0 to 20 and reversed to indicate lack of social support.

In the survey, the participants were asked how many times during the past 12 months they had become a victim of violence which left visible signs or were victims of threatening intimidation. The respondents who had become victims of either of these alternatives at least once were identified as cases.

\section{Clinical health examination}

Somatic health was determined in a standard 30-min clinical health examination carried out by a physician. Abnormal somatic health meant an abnormal status of the skin, respiratory, cardiovascular, abdominal, musculoskeletal or neurological systems.

Physical symptoms were queried during an interview before the physician's examination. Altogether, 13 questions with yes/ no alternative answers concerned respiratory symptoms (three questions), cardiovascular symptoms (four questions), allergic and other skin symptoms (four questions) and musculoskeletal symptoms (two questions). The number of symptoms was calculated as a simple sum of positive answers.

\section{Work factors}

\section{Survey}

Summary measures of self-assessed work factors were constructed on the basis of responses to the questionnaire.

Job demands ${ }^{33}{ }^{34}$ has five items (Cronbach's $\alpha=0.79$ ) (eg, "My job requires working very fast") ranging from 1 (strongly disagree) to 3 (neither disagree nor agree) to 5 (strongly agree).

Job control ${ }^{33} 34$ has nine items $(\alpha=0.85)$ (eg, "My job allows me to make a lot of decisions on my own"; "My job requires a high level of skill") ranging from 1 (strongly disagree) to 3 (neither disagree nor agree) to 5 (strongly agree). A reversed scale was calculated to indicate lack of job control.

Social support at work" ${ }^{33}{ }^{34}$ has two items ("I get support from my supervisor when needed"; "I get support from my coworkers when needed") $(\alpha=0.70)$ ranging from 1 (strongly disagree) to 3 (neither disagree nor agree) to 5 (strongly agree). A reversed scale was calculated to indicate lack of social support at work.

Educational prospects at work were assessed with a singleitem question as follows: "In your opinion, what in your current job, are your prospects of participating in education that develops your skills and abilities?" (response scale from 1 = very good to $3=$ neither good nor poor to $5=$ very poor).

Job insecurity was assessed by five questions estimating the threat of long-term unemployment, dismissal, decrease of tasks or transfer to another job ${ }^{41}$ (from $1=$ very little to $3=$ moderately to $5=$ very much $)(\alpha=0.94)$.

\section{Statistical analysis}

In tables 1 and 2 , the $p$ value for difference between the lowest and highest income categories was tested using the $\chi^{2}$ test and ANOVA. In table 3 , we used binary logistic regression models to calculate unadjusted odds ratios (OR) and their $95 \%$ confidence intervals $(95 \% \mathrm{CI})$ for the probability of having a DSM-IV depressive or anxiety disorder by each explanatory variable. Continuous variables were standardised before entering them into the models. In table 4, to evaluate the contribution of nonwork and work factors to the association between income level and depressive or anxiety disorders, we adjusted the models (in addition to age) for each variable separately and calculated the reduction (\%) in the excess risk. For both genders, only variables that were associated with both income level and mental health were taken into account $(p<0.10)$. We also assessed the contribution of all non-work and work factors by entering all (non-work and work) variables together into the models.

Weighting adjustment and sampling parameters were used in the analyses to account for the survey design complexities, including clustering in a stratified sample. The data were analysed using SAS/SUDAAN $9.0 .1^{42}$ because it is specifically designed for analysing cluster-correlated data in complex sample surveys. The weighting adjustment and sampling parameters allow the translation of sample data to population averages, as expressed by weighted percentages, means and OR using SAS/ SUDAAN procedures.

\section{RESULTS}

In our sample of a working population, the proportion of lowincome individuals was $9 \%$. Summaries of the descriptive statistics according to income level are presented in table 1 (men) and table 2 (women). Disadvantaged housing, lack of social support outside work, smoking, number of physical symptoms $(p=0.05)$, lack of job control, and lack of educational prospects at work were more prevalent among men with low income than among those with high income. For women, a significant association between income level and risk factors was found for all of the risk factors except for smoking $(p=0.07)$, somatic health status and social support at work.

We identified 108 (6\%) men and 208 (12\%) women as having at least one DSM-IV depressive or anxiety disorder. Table 3 shows the association of non-work and work factors with depressive or anxiety disorders among men and women. All work and non-work risk factors, except somatic health status and lack of social support outside work, were related to these disorders among men. Among women, all non-work and work risk factors except smoking ( $95 \%$ CI 0.99 to 1.94), were related to these mental disorders.

Table 4 presents the contribution of each risk factor separately and non-work and work factors together, to the association between income level and depressive or anxiety disorders. After adjustment for age, low income was related to a 2.8 times higher risk among men and a 2.0 times higher risk among women.

Among men, disadvantaged housing conditions (12\%) made the strongest contribution of the non-work factors, and all nonwork factors together explained $20 \%$ of the association. Of the work factors, the strongest contribution to the association between income and mental disorders among men was related to lack of educational prospects $(31 \%)$. Work factors together 
Table 1 Male characteristics according to income level $(n=1667)$

\begin{tabular}{|c|c|c|c|c|c|c|c|c|c|c|}
\hline \multirow[b]{3}{*}{ Characteristics } & \multicolumn{10}{|c|}{ Income level } \\
\hline & \multicolumn{3}{|c|}{ Low $(n=155)$} & \multicolumn{3}{|c|}{ Average $(n=897)$} & \multicolumn{3}{|c|}{ High $(n=615)$} & \multirow[b]{2}{*}{ p Value* } \\
\hline & Mean & SE & n (\%) & Mean & SE & n (\%) & Mean & SE & n (\%) & \\
\hline \multicolumn{11}{|l|}{ Non-work factors } \\
\hline Marital status & & & & & & & & & & 0.733 \\
\hline Married/co-habiting & & & $126(81.4)$ & & & $705(78.5)$ & & & $507(82.5)$ & \\
\hline Lack of social support outside work & 14.37 & 0.21 & & 13.57 & 0.10 & & 13.59 & 0.12 & & 0.001 \\
\hline Victim of violence & & & & & & & & & & 0.729 \\
\hline No & & & $140(92.6)$ & & & $825(93.0)$ & & & $559(91.8)$ & \\
\hline Yes & & & $11(7.4)$ & & & $62(7.0)$ & & & $50(8.2)$ & \\
\hline Smoking & & & & & & & & & & 0.033 \\
\hline No & & & $102(65.9)$ & & & $630(70.1)$ & & & $464(75.4)$ & \\
\hline Number of physical symptoms & & & & & & & & & & 0.050 \\
\hline 0 & & & $16(10.3)$ & & & $142(16.0)$ & & & $91(15.0)$ & \\
\hline $1-2$ & & & $67(43.6)$ & & & $412(46.4)$ & & & $285(46.7)$ & \\
\hline 3 or more & & & $72(46.2)$ & & & $333(37.7)$ & & & $234(38.3)$ & \\
\hline \multicolumn{11}{|l|}{ Work factors } \\
\hline Job demands & 3.19 & 0.07 & & 3.16 & 0.03 & & 3.17 & 0.04 & & 0.848 \\
\hline Lack of job control & 2.21 & 0.05 & & 2.29 & 0.02 & & 2.06 & 0.03 & & 0.015 \\
\hline Lack of social support at work & 2.28 & 0.09 & & 2.07 & 0.03 & & 2.14 & 0.04 & & 0.182 \\
\hline Lack of educational prospects at work & 2.98 & 0.09 & & 2.67 & 0.04 & & 2.42 & 0.04 & & $<0.001$ \\
\hline Job insecurity & 1.64 & 0.06 & & 1.68 & 0.03 & & 1.57 & 0.03 & & 0.276 \\
\hline
\end{tabular}

${ }^{*} p$ Value for difference ( $\chi^{2}$ test and ANOVA) between lowest and highest income categories. SE, standard error.

Table 2 Female characteristics according to income level $(n=1707)$

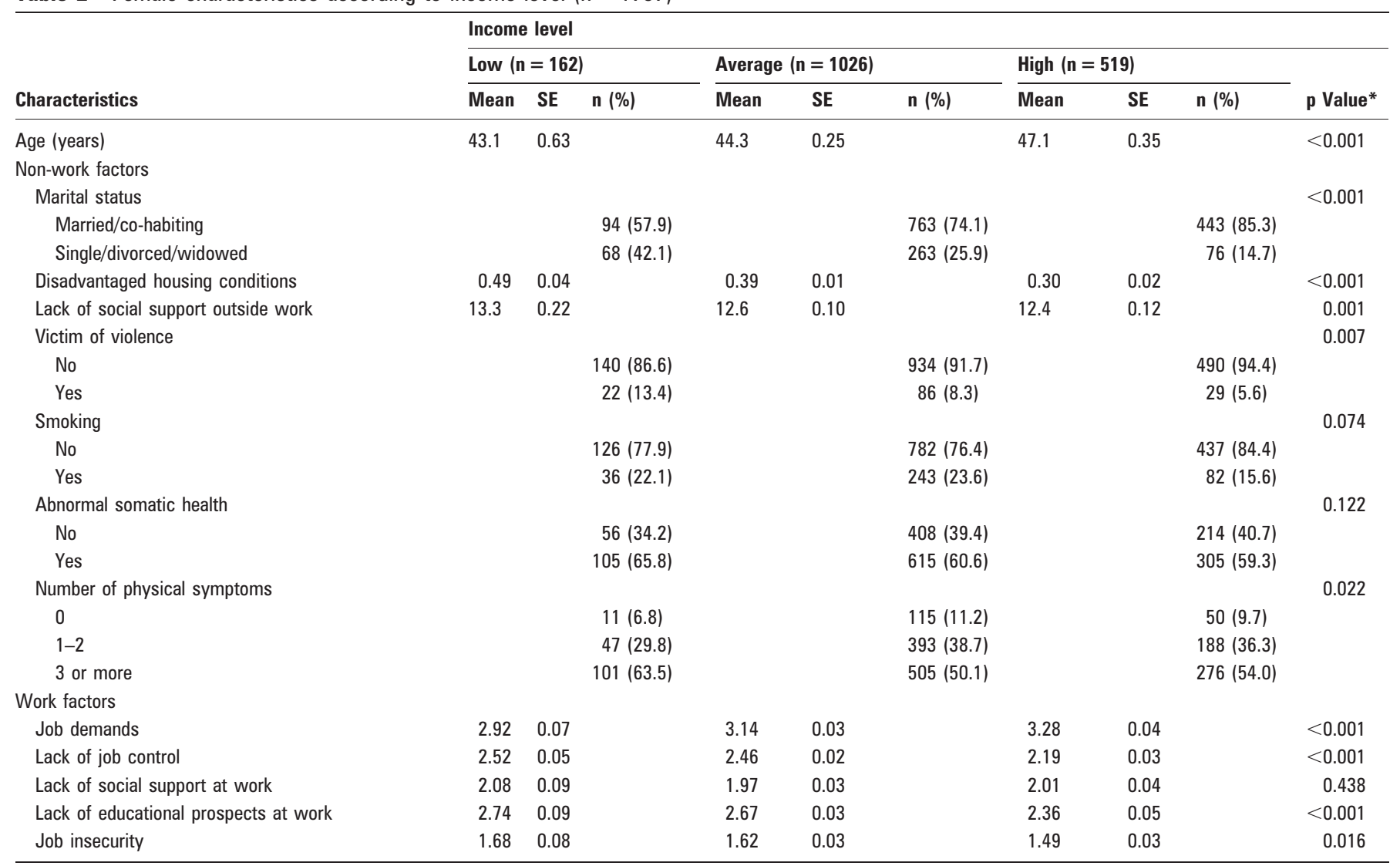

\footnotetext{
${ }^{*} p$ Value for difference ( $\chi^{2}$ test and ANOVA) between lowest and highest income categories. SE, standard error.
} 
Table 3 Association of non-work and work factors with the risk of 12-month depressive or anxiety disorder

\begin{tabular}{|c|c|c|}
\hline \multirow[b]{2}{*}{ Characteristics } & \multirow{2}{*}{$\begin{array}{l}\text { Men } \\
\text { OR }(95 \% \mathrm{CI})^{*}\end{array}$} & \multirow{2}{*}{$\begin{array}{l}\text { Women } \\
\text { OR }(95 \% \text { CI)* }\end{array}$} \\
\hline & & \\
\hline \multicolumn{3}{|l|}{ Non-work factors } \\
\hline Single/divorced/widowed vs married/co-habiting & 2.47 (1.63 to 3.75$)$ & 1.69 (1.23 to 2.32$)$ \\
\hline Disadvantaged housing conditions & $1.43(1.17$ to 1.76$)$ & $1.39(1.20$ to 1.60$)$ \\
\hline Lack of social support outside work & $1.23(0.94$ to 1.61$)$ & $1.23(1.06$ to 1.43$)$ \\
\hline \multicolumn{3}{|l|}{ Smoking } \\
\hline Yes vs no & 1.59 (1.07 to 2.36$)$ & $1.39(0.99$ to 1.94$)$ \\
\hline \multicolumn{3}{|l|}{ Abnormal somatic health } \\
\hline Yes vs no & $1.22(0.82$ to 1.80$)$ & 1.55 (1.15 to 2.09$)$ \\
\hline \multicolumn{3}{|l|}{ Number of physical symptoms } \\
\hline $1-2$ vs 0 & 1.44 (0.67 to 3.09 ) & 2.06 (1.04 to 4.09$)$ \\
\hline Lack of social support at work & $1.56(1.32$ to 1.84$)$ & $1.45(1.27$ to 1.65$)$ \\
\hline Lack of educational prospects at work & $1.71(1.37$ to 2.13$)$ & 1.25 (1.08 to 1.45$)$ \\
\hline Job insecurity & $1.52(1.27$ to 1.83$)$ & $1.23(1.08$ to 1.40$)$ \\
\hline
\end{tabular}

*Unadjusted. Cl, confidence interval; OR, odds ratio.

explained $31 \%$ of the association. All of the non-work and work factors together explained $37 \%$ of the association among men.

Among women, non-work factors had a major effect on the relationship between income level and mental disorders (table 4), the strongest contributions being marital status $(32 \%)$, disadvantaged housing (20\%) and lack of social support outside work (18\%). Non-work factors together explained 65\% of the association among women. Work factors had only a

Table 4 Contribution of non-work and work factors to the association between income level and the risk of 12-month depressive or anxiety disorder

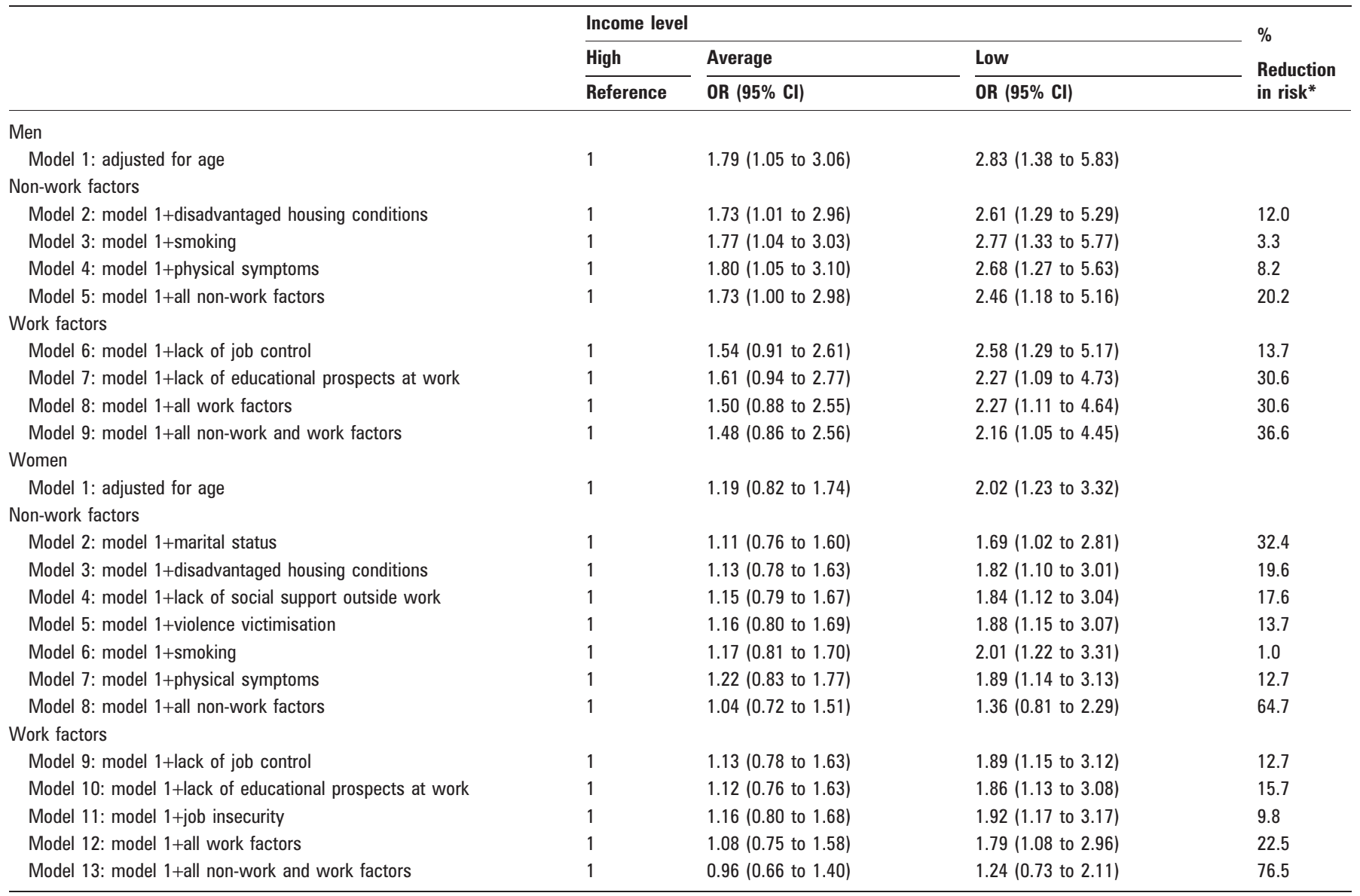

\footnotetext{
${ }^{*}$ Reduction in the excess risk between high and low income groups. $\mathrm{Cl}$, confidence interval; $\mathrm{OR}$, odds ratio.
} 
modest effect on the relationship between income level and mental health for women, the strongest effect being related to lack of educational prospects (16\%). Work factors together explained $23 \%$ of the association. All non-work and work factors together explained $77 \%$ of the association among women.

\section{DISCUSSION}

Evidence from this population-based study of 3374 Finnish working men and women confirmed the well-documented association between low income level and frequent mental disorders. While other studies have focused on socioeconomic health inequalities among general populations, we found a socioeconomic gradient in mental health was also present in a working population. We also examined the contribution of various non-work and work factors to the association between socioeconomic position and depressive and anxiety disorders using a standardised interview measuring DSM-IV diagnoses. Among men, work factors made a slightly greater contribution than non-work factors, but among women, non-work factors had a notably greater impact than work factors in explaining income differences with respect to mental health.

The risk of depressive or anxiety disorder was more than two times higher for employees in the lowest income group compared with those in the highest income group. This finding is in accordance with the findings of earlier cross-sectional and prospective studies. ${ }^{5-21}$ We determined the socioeconomic position of the participants using the definition of a lowincome expendable unit as suggested by the OECD. Using a definition close to ours, Bruce and her colleagues ${ }^{7}$ found that poverty was associated with the incidence of psychiatric disorders; in that study men and women were analysed together. Other measures of socioeconomic position (especially occupational status) have given inconsistent results. ${ }^{17}{ }^{19}$ Also in the Health 2000 Study, educational level was not related to mental disorders. ${ }^{4}$ It seems that low income as an indicator of social and material disadvantage is one of the best measures for determining the social determinants of the most frequent mental health problems. Low income may be the underlying factor for mental disorders since it imposes constraints on everyday life by reducing access to the elements that promote mental health, such as adequate housing and opportunities for relaxing leisure time activities.

Of the non-work factors, we did not find any socioeconomic gradient in somatic health status, although a statistically nonsignificant association was found. However, individuals with low income reported more physical symptoms than individuals with high income. Surprisingly, in men, we did not find any association between low income and violent victimisation (our measure included both physical and mental violence). It is possible that socioeconomic differences would have emerged with separate questions on physical and mental violence. However, the reasons behind the non-existent socioeconomic gradient in violence victimisation among men are unclear and need further consideration.

Among men, job demands were equal between socioeconomic categories, while among women, job demands were higher among those with high income. It is therefore possible that there are other job-related factors apart from job demands that explain the socioeconomic gradient in mental health.

With the exception of somatic health and non-work social support among men, and smoking among women, all of the risk factors studied were associated with the probability of 12month DSM-IV depressive or anxiety disorders. It is possible

\section{Main messages}

Socioeconomic inequalities in mental health are evident in a working population.

- In particular, work factors among men and non-work factors among women contribute to income differences as regards mental health.

\section{Policy implication}

Work and non-work factors should be taken into account when developing policies to reduce socioeconomic mental health differences.

that the lack of association between somatic ill health and mental disorders in men is simply related to weak statistical power. Furthermore, in the clinical health examination, only present clinical status and not severity of illness was taken into account. It is also possible that somatic illness had begun after any psychiatric episode, because the CIDI interview takes the previous 12 months into consideration while health status was based on the health examination at the time of the study.

We found that among men work factors had a slightly stronger contribution to differences than non-work factors with respect to mental disorders between income groups. In contrast, among women non-work factors had a major effect in explaining the association. For the latter group, we found the strongest attenuation in the association between income level and mental disorders was produced by marital status, housing conditions and lack of social support outside work. Single, divorced or widowed marital status usually means living without a partner, which has been associated with mental disorders in earlier research. ${ }^{24}{ }^{25}$ The mental health risk involved in living without a partner may be related, for example, to a lack of social support. Single mothers with children are also potentially among the low-income group and are exposed to several material and psychosocial stressors. In general, it seems that women are more vulnerable to domestic stressors, whereas men may be more vulnerable to work-related stressors. However, in our dataset, the examined variables were in general better able to explain income differences among women than among men. This may be due to fewer cases among men, or the inability of the chosen variables to take into account the associated elements with regard to socioeconomic position and men's mental health. Our results support explanations of the socioeconomic differences in mental health that underline the importance of poor living and working conditions, limitations on resources and subsequent negative social relationships.

The strength of our present study was the fact that our subjects were a representative sample of the Finnish working population aged 30-64 years and the high participation rate (83\% of the population of working age). Compared to participants in the CIDI interview, those who only attended the home interview have been found to have more symptoms in the $\mathrm{BDI}$, to be older, to more often be single or widowed and to have a low level of education, ${ }^{4}$ which may have affected our findings.

Our measure of household income was based on self-reports and should therefore be considered a proxy. In this study, we did not investigate other indicators of socioeconomic position, 
for example occupational grade. Further research is needed to examine whether using different indicators of socioeconomic positions would result in similar findings. The diagnoses of depressive and anxiety disorders were based on a valid interview instrument, the CIDI, ${ }^{38}$ and the prevalence of anxiety and depressive disorders was close to that found in other studies. ${ }^{3-5}$ Somatic health status was based on a comprehensive standard health examination by a research physician.

The main limitation of this study was its cross-sectional design, which limited conclusions about the direction of causality in the associations. Individuals with depressive or anxiety disorders may have been selected to low socioeconomic positions. We were not able to control for lifetime mental disorders in our study. However, health-based social selection has been shown to play only a minor role in explaining socioeconomic differences in mental disorders. ${ }^{8}{ }^{16}$ Another limitation is related to the variety of variables used in the study. In our dataset some important risk factors were not available, for example adverse life events. Also, we relied on selfreports regarding exposure to risk factors. More objective assessments might be better in future studies. Another problem is related to common method variance, that is, individuals with mental health problems may tend to perceive their environment as being more negative than other individuals. However, we found a large difference in the explanatory variables for mental health between men and women. It is unlikely that common method variance would have affected men and women so dissimilarly.

It should also be noted that the reduction in risk was inaccurate, as reflected, for example, by the $95 \%$ confidence interval for the low income OR for men which was 1.11 to 4.64 after adjustment for all work factors; this interval includes the OR estimate for low income adjusted for age alone (2.83). More research with larger sample sizes is needed to confirm that work factors significantly decrease the OR of income for mental disorders.

Finally, our sample was from the Finnish population, one of the countries in the world with low income inequality and a higher income per capita. Socioeconomic differences in mental health might be greater in countries where income inequalities are wider. ${ }^{43}$

In conclusion, we have shown that low income is also associated with the risk of having a depressive or anxiety disorder among a working population. Non-work and work factors make a significant contribution to the social inequalities found to accompany these frequent mental disorders in men and women. In order to promote mental health effectively in a working population, preventive policies should especially target people with low income.

Both work factors and non-work factors should be considered in policies to reduce socioeconomic mental health differences.

Acknowledgements: MK and JV were supported by the Academy of Finland (projects 105195 and 117604) and the Finnish Work Environment Fund.

Competing interests: None.

\section{REFERENCES}

1. Wells KB, Stewart $A$, Hays RD, et al. The functioning and well-being of depressed patients. JAMA 1989;262:914-19.

2. Gould R, Nyman H. Mielenterveys ja työkyvyttömyyseläkkeet [Mental health and work disability pensions] (in Finnish). Eläketurvakeskuksen monisteita 50, Helsinki, 2004.

3. Bijl RV, Ravelli A, van Zessen G. Prevalence of psychiatric disorder in the general population: results of The Netherlands Mental Health Survey and Incidence Study (NEMESIS). Soc Psychiatry Psychiatr Epidemiol 1998;33:587-95.
4. Pirkola S, Isometsä E, Suvisaari J, et al. DSM-IV mood, anxiety and alcohol use disorders and their comorbidity in the Finnish general population - results from the Health 2000 Study. Soc Psychiatry Psychiatr Epidemiol 2005;40:1-10.

5. WHO International Consortium in Psychiatric Epidemiology. Cross-national comparisons of the prevalences and correlates of mental disorders. Bull WHO 2000;78:413-26.

6. Lorant V, Deliege D, Eaton W, et al. Socioeconomic inequalities in depression: a meta-analysis. Am J Epidemiol 2003;157:98-112.

7. Bruce ML, Takeuchi DT, Leaf PJ. Poverty and psychiatric status: Iongitudinal evidence from the New Haven epidemiologic catchment area study. Arch Gen Psychiatry 1991;48:470-4.

8. Dohrenwend BP, Levav I, Shrout PE, et al. Socioeconomic status and psychiatric disorders: the causation-selection issue. Science 1992;255:946-52.

9. Kessler RC, McGonagle KA, Shanyang Z, et al. Lifetime and 12-month prevalence of DSM-II-R psychiatric disorders in the United States. Arch Gen Psychiatry 1994;51:819.

10. Dohrenwend BP, Schwartz S. Socioeconomic status and psychiatric disorders. Curr Opin Psychiatr 1995;8:138-41.

11. Jenkins R, Lewis G, Bebbington P, et al. The National Psychiatric Morbidity surveys of Great Britain--initial findings from the household survey. Psychol Med 1997:27:775-90.

12. Lewis G, Bebbington $P$, Brugha $T$, et al. Socioeconomic status, standard of living, and neurotic disorder. Lancet 1998;352:605-9.

13. Stansfeld SA, Head J, Marmot MG. Explaining social class differences in depression and well-being. Soc Psychiatry Psychiatr Epidemiol 1998:33:1-9.

14. Matthews S, Power C, Stansfeld SA. Psychological distress and work and home roles: a focus on socioeconomic differences in distress. Psychol Med 2001;31:72536.

15. Hunt C, Issakidis C, Andrews G. DSM-IV generalized anxiety disorder in the Australian National Survey of Mental Health and Well-Being. Psychol Med 2002;32:649-59.

16. Power C, Stansfeld SA, Matthews S, et al. Childhood and adulthood socio-economic differentials in psychological distress: evidence from the 1958 British birth cohort. Soc Sci Med 2002;55:1989-2004.

17. Araya R, Lewis G, Rojas G, et al. Education and income: which is more important for mental health? J Epidemiol Community Health 2003;57:501-5

18. Ferrie JE, Shipley MJ, Stansfeld SA, et al. Future uncertainty and socioeconomic inequalities in health: the Whitehall II study. Soc Sci Med 2003:57:637-46.

19. Fryers T, Melzer D, Jenkins R. Social inequalities and the common mental disorders A systematic review of the evidence. Soc Psychiatry Psychiatr Epidemiol 2003;38:229-37.

20. Stansfeld SA, Head J, Fuhrer R, et al. Social inequalities in depressive symptoms and physical functioning in the Whitehall II study: exploring a common cause explanation. J Epidemiol Community Health 2003;57:361-7.

21. Mojtabai R, Olfsson M. Major depression in community-dwelling middle-aged and older adults: prevalence and 2- and 4-year follow-up symptoms. Psychol Med 2004;34:623-34.

22. Merton RK. Social theory and social structure. Glencoe, IL: Free Press, 1957:131-60.

23. Blane DB. An assessment of the Black Report's explanation of health inequalities Sociol Health IIIn 1985;7:423-45.

24. Isometsä E. Masennushäiriöt [Depressive disorders]. In: Lönnqvist J, Heikkinen M Henriksson M, et al.Psykiatria [Psychiatry]. Helsinki: Duodecim, 2001:143-52.

25. Joutsenniemi $\mathbf{K}$, Martelin T, Martikainen $\mathrm{P}$, et al. Living arrangements and mental health in Finland. J Epidemiol Community Health 2006;60:468-75.

26. Muntaner C, Eaton WW, Miech R, et al. Socioeconomic position and major mental disorders. Epidemiol Rev 2004:26:53-62.

27. Harris T. Recent developments in understanding the psychosocial aspects of depression. Br Med Bull 2001;57:17-32.

28. Stansfeld S, Candy B. Psychosocial work environment and mental health--a metaanalytic review. Scand J Work Environ Health 2006;32:443-62.

29. Van der Doef M, Maes S. The Job Demand-Control(-Support) model and psychological well-being: a review of 20 years of empirical research. Work Stress 1999;13:87-144.

30. Wang J. Work stress as a risk factor for major depressive episode(s). Psychol Med 2005;5:865-71.

31. Ylipaavalniemi J, Kivimäki M, Elovainio M, et al. Psychosocial work characteristics and incidence of newly diagnosed depression: a prospective cohort study of three different models. Soc Sci Med 2005;61:111-22.

32. Godin I, Kittel F, Coppieters Y, et al. A prospective study of cumulative job stress in relation to mental health. BMC Public Health 2005;5:67.

33. Karasek RA. Job demands, job decision latitude and mental strain: implications for job redesign. Administative Science Quarterly 1979;24:285-308.

34. Karasek RA, Theorell T. Healthy work: stress, productivity, and the reconstruction of working life. New York: Basic Books, 1990.

35. Ferrie JE. Is job insecurity harmful to health? J $R$ Soc Med 2001;94:71-4.

36. Afifi M. Gender differences in mental health. Singapore Med J 2007:48:385-91.

37. Aromaa A, Koskinen S. Health and functional capacity in Finland. Baseline results of the Health 2000 health examination survey. Helsinki: National Public Health Institute, 2004 Available also at http://www.ktl.fi/health2000 (accessed 9 October 2007).

38. Jordanova V , Wickramesinghe $\mathrm{C}$, Gerada $\mathrm{C}$, et al. Validation of two survey diagnostic interviews among primary care attendees: a comparison of CIS-R and CIDI with SCAN ICD-10 diagnostic categories. Psychol Med 2004;34:1013-24. 
39. Alonso J, Angermeyer MC, Bernert S, et al. Prevalence of mental disorders in Europe: results from the European Study of the Epidemiology of Mental Disorders (ESEMeD) project. Acta Psychiatr Scand 2004;109(Suppl 420):21-7.

40. Sarason IG, Sarason BR, Shearin EN, et al. A brief measure of social support: practical and theoretical implications. Journal of Social and Personal Relationships 1987:4:497-510.
41. Lehto A-M. Työelämän laatu ja tasa-arvo tuotannossa. [The quality of working life and equality in production] (in Finnish). Helsinki: Statistics Finland, 1991.

42. RTI International. (SUDAAN) ${ }^{9}$. http://www.rti.org/sudaan/ (accessed 9 October 2007).

43. Kahn RS, Wise PH, Kennedy BP, et al. State income inequality, household income, and maternal mental and physical health: cross sectional national survey. BMJ 2000;321:13111-5.

\section{FUNDING AVAILABLE FOR RESEARCH PROJECTS}

The Committee on Publication Ethics (COPE) has established a Grant Scheme to fund research in the field of publication ethics. The Scheme is designed to provide financial support to any member of COPE for a defined research project that is in the broad area of the organisation's interests, and specifically in the area of ethical standards and practice in biomedical publishing. The project should have a specific goal and be intended to form the kernel of a future publication.

A maximum sum of $£ 5000$ will be allocated to any one project, but applications for smaller sums are welcomed.

The terms and conditions of the Grant are as follows:

- At least one of the applicants must be a member of COPE.

- Calls for applications will be made twice a year with closing dates of 1 December and 1 June. An electronic version of the application form must be sent to the Administrator no later than $12 \mathrm{pm}$ (noon GMT) on the closing date for consideration by COPE Council.

- The application must contain a lay summary of the project, a definition of the question to be posed, sufficient methodological detail to allow assessment of the viability of the project, a clear timeline and a definition of the likely deliverables. A full justification for the sum requested must accompany the application.

- A report on the progress of the research should be presented within one year of the award and at the end of the project. The grant must be used within two years from the date of award, and balance sheets must be forwarded annually. These should be sent to the Administrator. Any remaining funds after two years must be returned.

- It is anticipated that the work stemming from the project will be presented at one of COPE's annual seminar meetings within 2-3 years of the award. Such data may also be published in peer-reviewed journals. Any publications or related presentations at meetings by the recipient emanating in part or whole from COPE's support should be duly acknowledged and copies sent to the Administrator.

Applications are reviewed by a COPE sub-committee. Applicants will be advised of a decision as soon as practicable after the deadline date.

An application form can be obtained by contacting Linda Gough, COPE administrator, at LGough@ bmj.com or 0207383 6602. For more information on COPE, see http://www.publicationethics.org.uk/

The closing date for receipt of applications is 1 December 2007 or 1 June 2008. 